\title{
Dorsolateral Prefrontal Cortex GABA Concentration in Humans Predicts Working Memory Load Processing Capacity
}

\author{
Jong H. Yoon, ${ }^{1}$ Anthony Grandelis, ${ }^{2}$ and ${ }^{-R i c h a r d ~ J . ~ M a d d o c k ~}{ }^{2}$ \\ ${ }^{1}$ Department of Psychiatry and Behavioral Science, Stanford University, Palo Alto, California 94304, and ${ }^{2}$ Department of Psychiatry and Imaging Research \\ Center, University of California, Davis, California 95817
}

The discovery of neural mechanisms of working memory (WM) would significantly enhance our understanding of complex human behaviors and guide treatment development for WM-related impairments found in neuropsychiatric conditions and aging. Although the dorsolateral prefrontal cortex (DLPFC) has long been considered critical for WM, we still know little about the neural elements and pathways within the DLPFC that support WM in humans. In this study, we tested whether an individual's DLPFC gamma-aminobutryic acid (GABA) content predicts individual differences in WM task performance using a novel behavioral approach. Twenty-three healthy adults completed a task that measured the unique contribution of major WM components (memory load, maintenance, and distraction resistance) to performance. This was done to address the possibility that components have differing GABA dependencies and the failure to parse WM into components would lead to missing true associations with GABA. The subjects then had their DLPFC GABA content measured by single-voxel proton magnetic spectroscopy. We found that individuals with lower DLPFC GABA showed greater performance degradation with higher load, accounting for $31 \%$ of variance, $p_{\text {(corrected) }}=0.015$. This relationship was component, neurochemical, and brain region specific. DLPFC GABA content did not predict performance sensitivity to other components tested; DLPFC glutamate + glutamine and visual cortical GABA content did not predict load sensitivity. These results confirm the involvement of DLPFC GABA in WM load processing in humans and implicate factors controlling DLPFC GABA content in the neural mechanisms of WM and its impairments.

Key words: GABA; magnetic resonance spectroscopy; prefrontal cortex; working memory

\section{Significance Statement}

This study demonstrated for the first time that the amount of gamma-aminobutryic acid (GABA), the major inhibitory neurotransmitter of the brain, in an individual's prefrontal cortex predicts working memory (WM) task performance. Given that WM is required for many of the most characteristic cognitive and behavioral capabilities in humans, this finding could have a significant impact on our understanding of the neural basis of complex human behavior. Furthermore, this finding suggests that efforts to preserve or increase brain GABA levels could be fruitful in remediating WM-related deficits associated with neuropsychiatric conditions.

\section{Introduction}

Working memory (WM) can be defined as the temporary maintenance of information in a consciously accessible form, in which it

Received June 20, 2016; revised Aug. 24, 2016; accepted Sept. 19, 2016.

Author contributions: J.H.Y. designed research; J.H.Y. and A.G. performed research; J.H.Y., A.G., and R.J.M. analyzed data; J.H.Y. and R.J.M. wrote the paper.

This work was supported by the National Institutes of Health (Grant R21 MH090475).

The authors declare no competing financial interests.

Correspondence should be addressed to Jong H. Yoon, Department of Psychiatry and Behavioral Science, Stanford University, 3801 Miranda Ave., Palo Alto, CA 94304. E-mail: jhyoon1@stanford.edu.

DOI:10.1523/JNEUROSCI.1970-16.2016

Copyright $\odot 2016$ the authors $\quad 0270-6474 / 16 / 3611788-07 \$ 15.00 / 0$ can be efficiently manipulated, transformed, or used to guide goaldirected behavior. As such, WM is a cornerstone of human cognitive and behavioral capabilities, underlying some of our most characteristic and important behaviors such as multitasking and planning. Individual differences in diverse cognitive abilities, including general intelligence (Conway et al., 2003) and academic performance (Alloway and Alloway, 2010), are derived in part from individual differences in WM capacity. Conversely, WM impairments characterize a host of neuropsychiatric conditions, including schizophrenia (Goldman-Rakic, 1994) and cognitive decline associated with aging (Salthouse, 1990). Elucidating the neural mechanisms of WM would advance our understanding of WM-dependent cognitive and behav- 


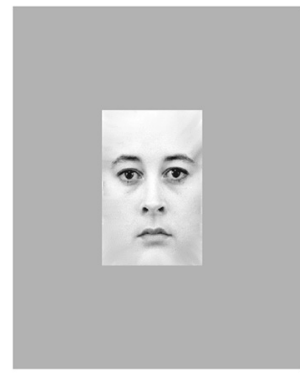

Cue $(2 \mathrm{sec})$ 1 or 2 faces

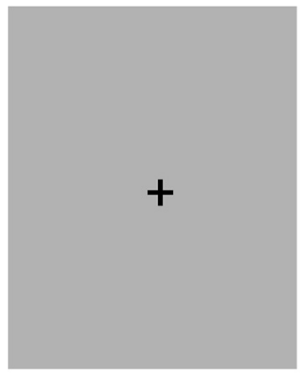

Delay ( 1 or $9 \mathrm{sec})$ Face shown in middle of delay period in Distractor trials

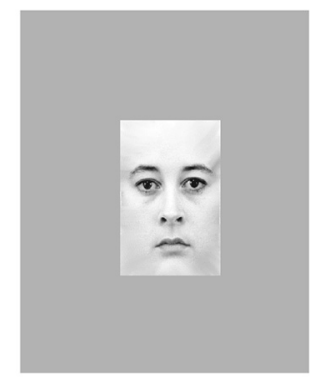

Probe (1 sec) $50 \%$ match probability

Figure 1. WM paradigm. The general trial structure shared by all trial types and examples of face stimuli are displayed. A trial starts with the presentation of face cue, which had to be maintained across a delay period to make a match discrimination with the probe face presented at the end of the delay period. This paradigm was designed to allow for the manipulation of specific WM components and the measurement of their effect on task performance. For example, the number of cue faces varied between 1 and 2 faces and the delay period varied between either 1 or $9 \mathrm{~s} \mathrm{so} \mathrm{that} \mathrm{we} \mathrm{could} \mathrm{measure} \mathrm{the} \mathrm{effect} \mathrm{of} \mathrm{longer} \mathrm{maintenance} \mathrm{requirements}$ and memory load on task performance, respectively. In conditions involving distraction, a single face was presented in the middle of the delay period for $1 \mathrm{~s}$. The effect of manipulating WM subcomponents was quantified by contrasting task performance (\% correct accuracy) between conditions that differed only in the subcomponent of interest. See text for details on task manipulations in each of the five conditions and planned contrasts between conditions.

ioral capabilities, as well as provide clues to the pathophysiology and remediation of WM deficits in pathological states.

The dorsolateral prefrontal cortex (DLPFC) is one of the most consistently implicated brain regions for WM (Cabeza and Nyberg, 2000). Although this mapping to the DLPFC is a useful starting point, a fundamental challenge for elucidating neural mechanisms is to determine the specific neural elements and processes within the DLPFC that are involved in WM. Among the neurochemicals thought to mediate DLPFC function and cognition, GABA has been the focus of considerable interest. GABAergic neurotransmission is thought to modulate and organize pyramidal neuron activity into synchronized gamma oscillations (Whittington and Traub, 2003; Cardin et al., 2009). Gamma oscillations are now recognized as a fundamental mechanism supporting information processing and cognition. Gamma activity has been implicated in higher-order cognition requiring WM and cognitive control (Tallon-Baudry et al., 1998; Howard et al., 2003; Meltzer et al., 2008) and intracranial recordings have localized load-dependent increases in gamma power to the DLPFC in humans (Howard et al., 2003; Meltzer et al., 2008). In schizophrenia, the loss of DLPFC GAD67 (Akbarian et al., 1995; Guidotti et al., 2000; Volk et al., 2000; Hashimoto et al., 2008), the major synthetic enzyme for GABA, in interneurons is hypothesized to result in reductions in GABA synthesis, GABAergic neurotransmission, and gamma-band activity, as well as WM deficits (Lewis and Gonzalez-Burgos, 2006). Evidence from human studies suggests a link between gamma oscillations and cortical GABA content (Muthukumaraswamy et al., 2009; Chen et al., 2014).

Although this model provides a compelling and detailed neurobiological framework for the study of WM, direct evidence linking DLPFC GABA and WM in humans has been sparse. Magnetic resonance spectroscopy (MRS) is a neuroimaging modality that can quantify the concentration of specific neurochemicals in the brain, including GABA. MRS can be combined with WM tasks to test for a quantitative association between individual differences in DLPFC GABA content and task performance. Finding a positive association would suggest that an individual's available pool of DLPFC GABA indexes the functional capacity of GABAergic interneurons and constrains WM performance. This demonstration would also validate in vivo GABA MRS measures as a brain-based biomarker with potential utility for future clinical studies and further studies of GABA's role in WM in humans.

Here, we used a novel behavioral approach to test the hypothesis that individuals' GABA levels within the DLPFC predict their WM performance. WM is a multifaceted construct composed of multiple component processes (GoldmanRakic, 1996; Baddeley, 2003), which are likely supported by distinct neurobiological mechanisms with possibly variable GABA dependencies. Global measures of WM performance reflect the combined effects of these components, which could obscure links with GABA. Fractionating WM into component processes may facilitate the detection of its associations with GABA. Therefore, we used a WM paradigm designed to measure the unique contribution of three WM components (memory load, maintenance, and distraction resistance) to task performance. A sample of healthy adults completed this WM paradigm and underwent single-voxel proton MRS to estimate their DLPFC GABA content. We then tested whether individuals' DLPFC GABA levels predicted their performance sensitivity to changes in these three WM component processes.

\section{Materials and Methods}

Subjects. Twenty-three healthy young adults completed this study. The mean age of the sample was 22.4 years $(\mathrm{SD}=3.3)$ and $70 \%$ were men. Exclusion criteria were as follows: intelligence quotient of $<70$, drug or alcohol dependence or abuse within 3 months of testing, a positive urine drug screen on the day of testing, medical or neurological illness affecting brain function, history of significant head trauma, lifetime diagnosis of a major Axis I disorder, or a first-degree relative with a psychotic disorder. We also applied an a priori specified task performance criterion to exclude subjects with motivation or attention difficulties. Subjects had to attain $>90 \%$ accuracy on the baseline condition of the WM paradigm for inclusion (Fig. 1). The baseline condition was relatively simple, with minimal WM or cognitive demands. Therefore, we expected only subjects with substantial motivation or attention problems to achieve subthreshold performance. Two subjects enrolled in the study failed to achieve threshold performance and were excluded. The demographics of the final sample were as follows: 17 males, 6 females; mean age 22.4 years old (SD 3.0 years, range 19-32). This study was approved by the Institutional Review Board at the University of California-Davis and all subjects provided written informed consent for all procedures.

Spectroscopy methods. We conducted single-voxel proton MRS on the Siemens MAGNETOM Tim Trio 3T MRI system using the Siemens 32channel head coil. We used a Siemens Works-in-Progress (WIP) sequence (Heberlein and Brown, 2009) to measure GABA. It provides water-suppressed single-voxel spectroscopy with J-difference spectral editing that enables the GABA resonance at $2.99 \mathrm{ppm}$ to be distinguished from the overlapping creatine $(\mathrm{Cr})$ singlet, as well as removing other overlapping signals (Mescher et al., 1996; Mescher et al., 1998; Henry et al., 2001). This is achieved through the subtraction of two independently acquired spectra that have GABA J-coupled resonances of opposite polarity at $\sim 2.99 \mathrm{ppm}$. MRS spectra were acquired using the following parameters: $1500 \mathrm{~ms}$ TR; $68 \mathrm{~ms}$ TE; $852 \mathrm{~ms}$ acquisition duration; 16 step EXOR phase cycling; 1024 data points; $1200 \mathrm{~Hz}$ receiver bandwidth; 1.9 ppm edit pulse on resonance frequency; $7.5 \mathrm{ppm}$ edit pulse off resonance frequency; $-1.7 \mathrm{ppm}$ delta frequency; $45 \mathrm{~Hz}$ edit pulse bandwidth. In each scan, acquisitions in which the spectral editing pulse was applied on 
A

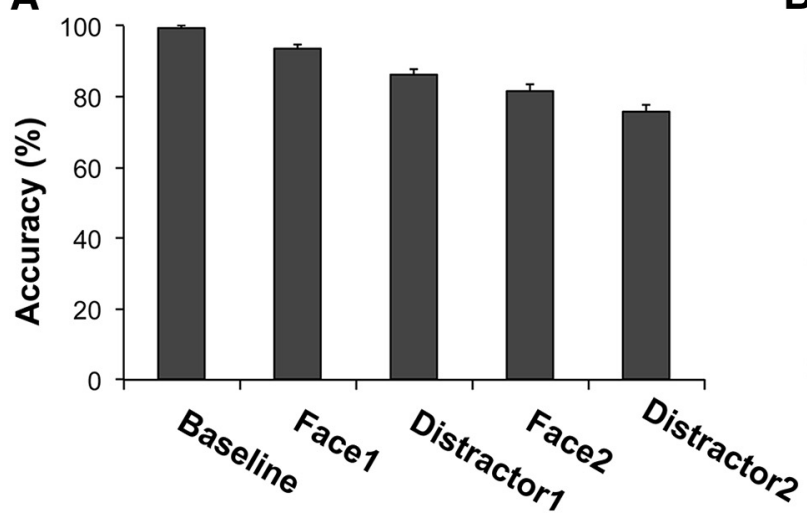

B

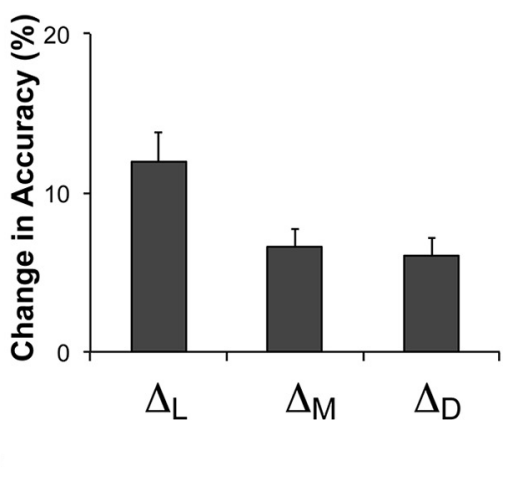

Figure 2. Task performance results. $\boldsymbol{A}$, Group means of percentage task accuracy for the five conditions in the WM paradigm. $\boldsymbol{B}$, Group means of the change in task accuracy with manipulation of the three WM components, $\Delta_{L^{\prime}} \Delta_{M}$, and $\Delta_{D}$. Error bars indicate SEM.

resonance were interleaved with those in which the pulse was applied off resonance for a total of 256 acquisitions in each of three consecutive 6.4 min scans in the 2 brain regions studied (DLPFC and visual cortex). The water frequency was adjusted before each 6.4 min scan. GABA content measured by this method includes signal from macromolecules and homocarnosine that coedit with GABA.

To sample the DLPFC, a $30 \times 15 \times 35 \mathrm{~mm}$ voxel in the $x, y, z$ dimensions was placed within the boundaries formed by the left middle frontal gyrus voxel, the precentral sulcus, the superior-lateral extent of the cerebrum, and the superior frontal sulcus (Fig. 1). To test for the specificity of our DLPFC findings, we also obtained MRS measurements from early visual cortex. We centered a $35 \times 30 \times 25 \mathrm{~mm}$ voxel on the calcarine sulci bilaterally, with the voxel's posterior border $7 \mathrm{~mm}$ anterior to the dura. We used different voxel dimensions in sampling the DLPFC and visual cortex brain regions to maximize sampling of gray matter in each region. Anatomical landmarks were visualized on a 3D high-resolution T1-weighted structural image obtained just before GABA spectroscopy scans.

Using jMRUI software, all pairs of on- and off-resonance spectra were phase aligned with reference to water, zero filled from 1024 to 4096, apodized with a $4 \mathrm{~Hz}$ Gaussian filter, and frequency aligned to $\mathrm{Cr}$ at 3.02 ppm. Peak integration was used to quantify total GABA $(2.99 \pm 0.12$ $\mathrm{ppm})$ and combined glutamine plus glutamate $(\mathrm{Glx})(3.76 \pm 0.11 \mathrm{ppm})$ in the difference spectra and $\mathrm{Cr}(3.02 \pm 0.09 \mathrm{ppm})$ in the summed spectra, as described previously (Yoon et al., 2010). One of the authors (R.J.M.), blinded to WM performance, visually inspected the spectra from each 6.4 min acquisition to identify and exclude any scans with obvious artifact (Yoon et al., 2010). The ratio of total GABA/total Cr signal averaged across all scans in each brain region was used for hypothesis testing. Normalizing to $\mathrm{Cr}$ reduces intersubject variance attributable to differences in global signal strength and CSF fraction within the voxel and has been shown to yield reliable GABA concentration estimates (Bogner et al., 2010).

WM paradigm. We designed a WM paradigm (Fig. 1) and analytic plan that quantified the unique contribution of specific WM components to task performance so that associations between GABA levels and WM components could be tested. Because we did not have strong a priori predictions of which WM component would be linked with GABA, we examined three of the most commonly studied components of WM: memory load (L), maintenance (M), and distraction resistance (D). Our WM paradigm allowed us to manipulate levels of difficulty for these components and measure their effects on task performance. For example, to quantify the effect of load on performance, we designed two conditions with identical task demands, except for the memory load (e.g., one vs two cue items). Performance sensitivity to memory load was estimated for each individual by calculating the change in task accuracy across the high- and low-load conditions. Individuals' change scores were then correlated with their DLPFC GABA concentrations.

We used a delayed response WM task for this experiment because it readily allowed for the separation and manipulation of the three WM components of interest. All trials of the experiment had the following general structure. The trial started when a cue face(s) was presented for $2 \mathrm{~s}$, which was followed by a delay period. At the end of the delay period, a single probe face was presented, prompting the subject to make an identity match discrimination between the probe and cue stimuli. Matches occurred with $50 \%$ probability. Subjects completed the following five trial types/conditions in which we manipulated specific task components while retaining the overall cue-delay-probe structure: (1) baseline: 1 cue face, short delay (1 s), probe; (2) Facel: 1 cue face, long delay (9 s), probe; (3) Face2: 2 cue faces, long delay, probe; (4) Distractor1: 1 cue face, long delay with distractor face presented for $1 \mathrm{~s}$ in the middle of the delay, probe; and (5) Distractor2: 2 cue faces, long delay with distractor, probe. In all trials, one face was presented in the probe phase. Twenty-eight trials for each condition were presented. To quantify task performance sensitivity to the manipulation of specific WM components, we calculated the following change in task accuracy for each of the components as follows: (1) $\Delta_{\mathrm{L}}=\%$ accuracy Face $1-\%$ accuracy Face $2 ;(2) \Delta_{\mathrm{M}}=\%$ accuracy Baseline $-\%$ accuracy Face1; $\Delta_{\mathrm{D}}=[(\%$ accuracy Face1 - \% accuracy Distractor 1$)+(\%$ accuracy Face $2-\%$ accuracy Distractor2)]/2.

An additional advantage of relating GABA to individual WM components is the greater specificity of inferences on neural mechanisms that could be made with positive findings. The set of neural processes underlying WM components is more restricted and better defined compared with those for overall WM. Therefore, a link between GABA and a specific WM component could point to GABA involvement in more limited and specified set of neural processes. The use of between-condition differences in task performance accuracy also controlled for variability in nonspecific factors that could be strong determinants in individual differences in task performance. These determinants, if not controlled, could obscure our ability to detect true associations between GABA levels of WM task performance.

Statistical analysis. We tested our hypothesis with Pearson's correlations between DLPFC GABA content and $\Delta_{\mathrm{L}}, \Delta_{\mathrm{M}}$, and $\Delta_{\mathrm{D}}$. In determining statistical significance, we used two-tailed tests and corrected for multiple comparisons with a Bonferroni factor of 3 . Corrected $p$-values are indicated as $p_{\text {(corrected) }}$. For example, $p_{\text {(corrected) }}=0.015$ is equivalent to an uncorrected $p=0.005$. There were instances in which Bonferroni correction resulted in nonsensical values; for example, when the uncorrected $p$-values were $>0.33$, corrected $p$-values were $>1.0$. In these instances, we set the $p$-values to 1.000 .

\section{Results}

\section{Task performance results}

The means of subjects' performance across the experimental manipulations of WM components are displayed in Figure $2 A$. Task accuracy decreased in a monotonic fashion across conditions from nearly $100 \%$ accuracy in the baseline condition to the most 
A

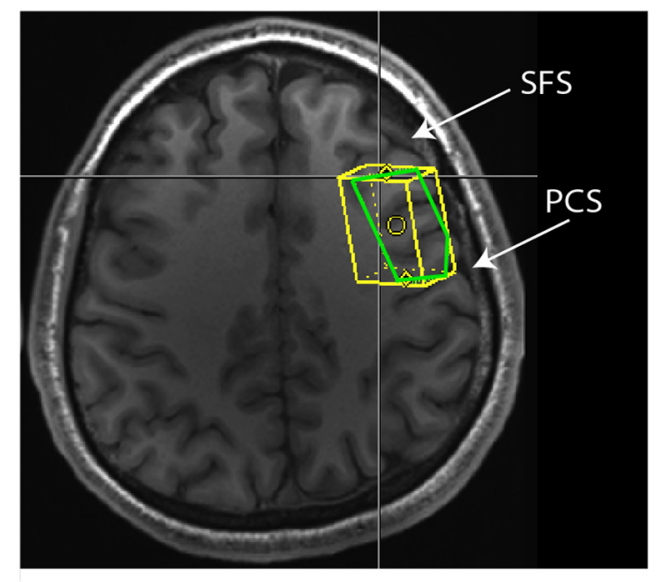

B

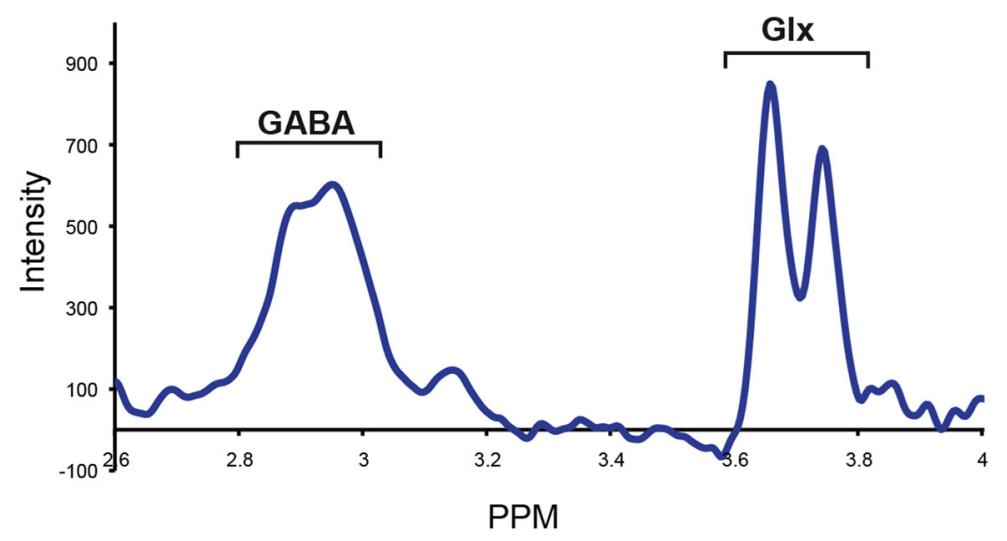

Figure 3. GABA spectroscopy. $A$, Example of the voxel position within the left middle frontal gyrus in a representative subject. The irregular shape of the in-plane section (green lines) of the voxel is the result of having to rotate the voxel obliquely in reference to the slice plane of the structural images. SFS, Superior frontal sulcus; PCS, precentral sulcus. $\boldsymbol{B}$, Group-averaged edited spectra from the middle frontal gyrus show the characteristic pseudo-doublet peak of the GABA line graph at $\sim 3.0 \mathrm{ppm}$ and the doublet peak of Glx at $\sim 3.7 \mathrm{ppm}$.

A

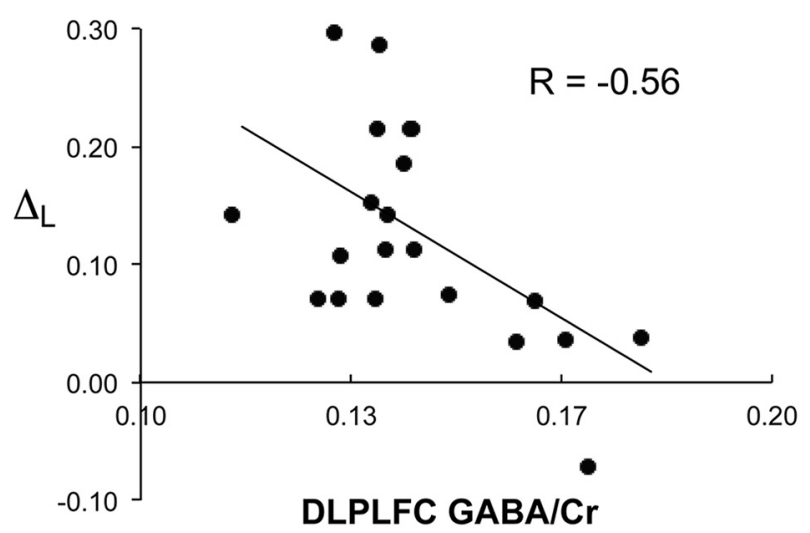

B

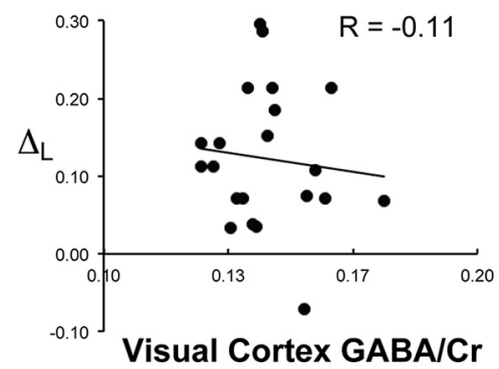

C

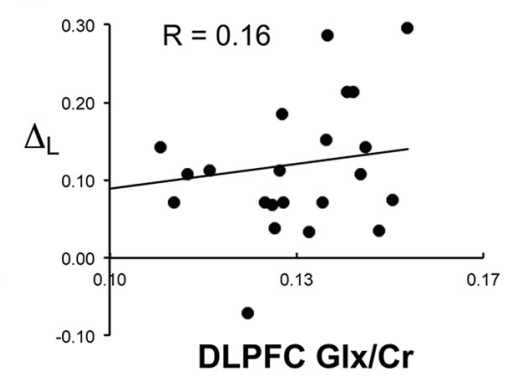

Figure 4. Specificity of subjects' DLPFC GABA content correlation with task performance sensitivity to memory load. Scatter plot of individual subject's DLPFC GABA content ( $x$-axis) plotted against $\Delta_{\mathrm{L}}$ ( $y$-axis), change in task accuracy across levels of memory load $(\boldsymbol{A})$; visual cortex GABA content plotted against $\Delta_{\mathrm{L}}(\boldsymbol{B})$; and DLPFC Glx plotted against $\Delta_{\mathrm{L}}(\boldsymbol{C})$

difficult condition, Distractor2. The mean accuracies for all conditions in the order of highest to lowest accuracy, with SD provided in parentheses, were as follows: baseline $=99.6 \%(1.9)$; Face $1=93.6 \%$ (6.1); Distractor $1=86.1 \%(7.2)$; Face $2=81.6 \%$ (9.6); and Distractor $2=76.0 \%$ (9.3). In the planned comparisons between conditions, we observed the following percentage change in task accuracy in response to WM component manipulations (Fig. $2 B): \Delta_{\mathrm{L}}=12.0(\mathrm{SD}=8.6), \Delta_{\mathrm{M}}=6.6(\mathrm{SD}=5.7)$, and $\Delta_{\mathrm{D}} 6.0(\mathrm{SD}=5.2)$.

\section{GABA MRS results}

The voxel location within the DLPFC from a representative subject and group-averaged edited spectra are shown in Figure 3. No scans were excluded due to motion or other artifact. Due to technical difficulties, we were unable to acquire all three scans in each brain region for some subjects. For the DLPFC, only two scans were acquired in two subjects and one scan in one subject. For the visual cortex, only two scans were acquired in two subjects. Mean DLPFC GABA/Cr and Glx/Cr levels in our sample were $0.146(\mathrm{SD}=0.016)$ and 0.131 ( $\mathrm{SD}=0.015)$, respectively (Fig. 4). Mean visual cortex GABA/Cr and $\mathrm{Glx} / \mathrm{Cr}$ levels were $0.146(\mathrm{SD}=0.013)$ and 0.128 $(\mathrm{SD}=0.014)$, respectively.

\section{Correlation between task performance and GABA/Cr content}

The correlation between DLPFC GABA/Cr and $\Delta_{\mathrm{L}}$ was significant $\left(r=-0.564, p_{\text {(cor- }}\right.$ rected) $=0.015, n=23$ ). DLPFC GABA/Cr correlation with $\Delta_{\mathrm{M}}\left(r=0.464, p_{\text {(corrected) }}=\right.$ $0.078, n=23)$ and with $\Delta_{\mathrm{D}}\left(r=0.003, p_{\text {(cor }}\right.$ rected) $=1.000, n=23$ ) were nonsignificant. The level of correlation between DLPFC GABA/Cr and $\Delta_{\mathrm{L}}$ was significantly different from that of DLPFC GABA/Cr and $\Delta_{\mathrm{M}}(z=$ 2.870, $p=0.004)$ and DLPFC GABA/Cr and $\Delta_{\mathrm{D}}(z=5.103, p<0.001)$. We next examined the neurochemical and regional specificity of our findings. The correlation between DLPFC Glx/Cr and $\Delta_{\mathrm{L}}$ was nonsignificant $(r=0.157, p=$ $0.475, n=23)$ and differed significantly from the correlation between DLPFC GABA/Cr and $\Delta_{\mathrm{L}}(z=3.564, p<0.001)$. The correlation between visual cortical GABA/Cr and $\Delta_{\mathrm{L}}$ was nonsignificant $(r=-0.112, p=0.611, n=23)$ and differed significantly from the correlation between DLPFC GABA/Cr and $\Delta_{\mathrm{L}}(z=2.353, p=$ 0.019). Excluding subjects with fewer than three acquisitions in DLPFC or visual cortex did not change this pattern of findings. 


\section{Discussion}

We observed a significant association between subjects' DLPFC GABA content and WM load processing. Subjects with lower GABA showed greater degradation of performance in trials with higher memory load. Conversely, subjects with higher GABA showed less performance degradation with higher load. This association was specific; DLPFC GABA content did not correlate with task performance sensitivity to the other components tested. Furthermore, the association with load was region and neurochemical specific; neither DLPFC Glx nor visual cortical GABA content exhibited this association. To the best of our knowledge, the present study is the first demonstration of an in vivo measure of DLPFC GABA predicting individual differences in WM performance in humans. This finding adds to the rationale for focusing on DLPFC GABA and related neural systems in further elucidating the neural mechanisms of WM, as well as the pathophysiology of neuropsychiatric conditions involving WM deficits.

Two features of our experimental design likely facilitated the detection of an association between individual differences in task performance and DLPFC GABA content. The first feature was the use of a change in performance instead of an absolute measure of performance; the former controls for nonspecific determinants of task performance, which could vary substantially across subjects and obscure the detection of associations with specific determinants. Another important feature was the focus on WM components. WM is composed of multiple component processes, which may rely on distinct sets of neural mechanisms (Goldman-Rakic, 1996) and have variable degree of GABA dependency. Threfore, the combination of the use of change scores and focus on components may have optimized this study's chances of detecting an association with DLPFC GABA levels. The specificity of our findings builds upon a prior MRS study that reported dynamic changes in DLPFC GABA levels during the completion of a WM task, rising early and then declining later in the course of WM task performance compared with baseline levels (Michels et al., 2012). However, in this prior study, baseline GABA measurements using MEGA PRESS were preceded by EPIbased scans. GABA measurements preceded by EPI-based scans have been shown recently to result in time-sensitive underestimation of true GABA levels (Harris et al., 2014). Therefore, future studies will be required to confirm dynamic changes in DLPFC GABA levels during the completion of WM tasks.

Our main finding of an inverse correlation between DLPFC GABA content and $\Delta_{\mathrm{L}}$, change in task performance with higher memory load, suggests that DLPFC GABA content is a determinant of WM storage capacity. WM storage capacity refers to the number of items that can be held in WM at a single point in time. Although we did not quantify WM capacity in this study, most established methods for estimating this parameter involve measuring changes in accuracy as a function of increasing memory load (Luck and Vogel, 1997; Cowan, 2001). Therefore, it would be reasonable to expect that $\Delta_{\mathrm{L}}$ reflects to some degree WM storage capacity. The degradation in performance quantified by $\Delta_{\mathrm{L}}$ could be due to the processing demands imposed by the higher memory load exceeding neural resource constraints. Our results suggest that DLPFC GABA content could be one of these neural constraints. Individual differences in WM capacity are thought to contribute to individual differences in a number of cognitive attributes such as fluid intelligence and overall academic performance (Conway et al., 2003; Alloway and Alloway, 2010). Therefore, vari- ability in DLPFC GABA content could be contributing to individual differences in these WM-capacity-related attributes.

The results of the present study interpreted in the context of the relevant literature suggest a plausible mechanism by which DLPFC GABA may mediate WM load processing. Current neurobiological models of WM ascribe executive control functions to the DLPFC (Curtis and D'Esposito, 2003; Postle, 2006). The DLPFC is thought to exert executive control over posterior cortical areas where representations of the memoranda are stored and actively maintained during WM. The strength of the DLPFC signal to the posterior cortex has been proposed in computational models to boost the load capacity and processing of these posterior cortical representations in WM (Edin et al., 2009). The relevance of DLPFC signal strength to WM capacity is supported by a number of fMRI studies that have documented higher fMRI signals in the DLPFC with higher WM load (Braver et al., 1997; Rypma and D'Esposito, 1999; Linden et al., 2003). Through GABA's well recognized role in establishing high-frequency gamma-band oscillations within populations of neocortical pyramidal neurons, GABA content could be an important parameter determining DLPFC signal strength. Studies have demonstrated load-specific increases in gamma power within the PFC and other cortical regions during WM (Howard et al., 2003; Meltzer et al., 2008). A number of recent studies have reported links between cortical GABA concentration and parameters of gamma oscillations (Edden et al., 2009; Gaetz et al., 2011; Chen et al., 2014). These include peak gamma frequency during the encoding stage of the WM task correlating with GABA level and WM performance (Chen et al., 2014). Finally, deficiencies in the production of GABA in GABAergic interneurons are hypothesized to underlie the impairments in gamma-band oscillations (Lewis et al., 2005; Cho et al., 2006; Minzenberg et al., 2010) and higherorder cognitive deficits, including WM, in schizophrenia. In the context of this evidence, our findings are consistent with the possibility that DLPFC GABA supports load processing by promoting gamma oscillations and greater DLPFC signaling to posterior cortex.

Another plausible mechanism by which DLPFC GABA may influence WM capacity is suggested by computational spiking network models of WM. These models propose that excitatory/ inhibitory balance within cortical microcircuits determines the tuning properties of WM-stimulus-selective activations underlying WM capacity (Wei et al., 2012). Inactivation of inhibition has been shown to broaden this tuning and account for the propensity to commit false alarm errors during WM task performance in humans given pharmacological agents targeting the disruption of GABAergic interneuron function (Murray et al., 2014). We were, however, unable to test this prediction in our dataset due to the low number of false alarm trials in our experiment.

Our results may have implications for the development of treatments for WM deficits and WM-related cognitive and behavioral abnormalities associated with neuropsychiatric conditions. Neuronal GABA is produced by glutamic acid decarboxylase (GAD). GAD67 is one of its major isoforms and it potently controls wholecell content of GABA (Asada et al., 1997). Downregulation of this enzyme is thought to be a source of GABAergic dysfunction and WM and related cognitive deficits in schizophrenia (Lewis et al., 2005). Our results suggest that treatments promoting GABA synthesis could be useful in this and possibly other conditions involving WM and GABA deficits. A related strategy could be to improve postsynaptic signaling of GABA with a GABA receptor agonist. One study of this approach in schizophrenia found improved performance in a WM-dependent higher-order cognitive task, accompa- 
nied by increase task-evoked gamma oscillation (Lewis et al., 2008). However, another study using the same strategy did not show an effect on cognition in schizophrenia (Buchanan et al., 2011).

It is important to note that MRS measures the total tissue content of GABA within a region. Most brain tissue GABA is in the cytosolic or vesicular compartments of GABAergic neurons. The amount of GABA in the extracellular fluid is several orders of magnitude less than that found in these intracellular compartments (Wu et al., 2007). MRS cannot sample vesicular versus cytosolic GABA selectively. Vesicular GABA plays a direct role in GABAergic neurotransmission. Although GABA in the cytosol can serve nonsignaling metabolic functions under some conditions, cytosolic GABA concentration may also be a critical determinant of vesicular filling in GABAergic interneurons (Hartman et al., 2006; Lau and Murthy, 2012). Some studies also suggest that cytosolic GABA may serve as a reservoir for nonsynaptic GABAergic signaling ( $\mathrm{Wu}$ et al., 2007). In addition, the total tissue content of GABA may reflect the density and functional integrity of GABAergic neurons within a region. Our findings suggest that total tissue GABA content in the DLPFC reflects a functionally meaningful parameter that influences WM capacity.

This study demonstrated an inverse correlation between in vivo DLPFC GABA levels measured by MRS and task performance sensitivity to WM load, indicating that the amount of GABA in the DLPFC is a critical variable supporting WM capacity. This finding also suggests that the further study of GABA in the DLPFC and the neural factors affecting GABA content in this region could lead to a more complete account of the neural mechanisms of WM, as well as reveal potential strategies to remediate deficiencies in WM capacity associated with a number of neuropsychiatric conditions.

\section{References}

Akbarian S, Kim JJ, Potkin SG, Hagman JO, Tafazzoli A, Bunney WE Jr, Jones EG (1995) Gene expression for glutamic acid decarboxylase is reduced without loss of neurons in prefrontal cortex of schizophrenics. Arch Gen Psychiatry 52:258-266. CrossRef Medline

Alloway TP, Alloway RG (2010) Investigating the predictive roles of working memory and IQ in academic attainment. J Exp Child Psychol 106: 20-29. CrossRef Medline

Asada H, Kawamura Y, Maruyama K, Kume H, Ding RG, Kanbara N, Kuzume H, Sanbo M, Yagi T, Obata K (1997) Cleft palate and decreased brain gamma-aminobutyric acid in mice lacking the $67-\mathrm{kDa}$ isoform of glutamic acid decarboxylase. Proc Natl Acad Sci U S A 94:6496-6499. CrossRef Medline

Baddeley A (2003) Working memory: looking back and looking forward. Nat Rev Neurosci 4:829-839. CrossRef Medline

Bogner W, Gruber S, Doelken M, Stadlbauer A, Ganslandt O, Boettcher U, Trattnig S, Doerfler A, Stefan H, Hammen T (2010) In vivo quantification of intracerebral GABA by single-voxel (1)H-MRS-How reproducible are the results? Eur J Radiol 73:526-531. CrossRef Medline

Braver TS, Cohen JD, Nystrom LE, Jonides J, Smith EE, Noll DC (1997) A parametric study of prefrontal cortex involvement in human working memory. Neuroimage 5:49-62. CrossRef Medline

Buchanan RW, Keefe RS, Lieberman JA, Barch DM, Csernansky JG, Goff DC, Gold JM, Green MF, Jarskog LF, Javitt DC, Kimhy D, Kraus MS, McEvoy JP, Mesholam-Gately RI, Seidman LJ, Ball MP, McMahon RP, Kern RS, Robinson J, Marder SR (2011) A randomized clinical trial of MK-0777 for the treatment of cognitive impairments in people with schizophrenia. Biol Psychiatry 69:442-449. CrossRef Medline

Cabeza R, Nyberg L (2000) Imaging cognition II: An empirical review of 275 PET and fMRI studies. J Cogn Neurosci 12:1-47. Medline

Cardin JA, Carlén M, Meletis K, Knoblich U, Zhang F, Deisseroth K, Tsai LH, Moore CI (2009) Driving fast-spiking cells induces gamma rhythm and controls sensory responses. Nature 459:663-667. CrossRef Medline

Chen CM, Stanford AD, Mao X, Abi-Dargham A, Shungu DC, Lisanby SH, Schroeder CE, Kegeles LS (2014) GABA level, gamma oscillation, and working memory performance in schizophrenia. Neuroimage Clinical 4:531-539. CrossRef Medline

Cho RY, Konecky RO, Carter CS (2006) Impairments in frontal cortical gamma synchrony and cognitive control in schizophrenia. Proc Natl Acad Sci U S A 103:19878-19883. CrossRef Medline

Conway AR, Kane MJ, Engle RW (2003) Working memory capacity and its relation to general intelligence. Trends Cogn Sci 7:547-552. CrossRef Medline

Cowan N (2001) The magical number 4 in short-term memory: a reconsideration of mental storage capacity. Behav Brain Sci 24:87-114; discussion 114-185. Medline

Curtis CE, D'Esposito M (2003) Persistent activity in the prefrontal cortex during working memory. Trends Cogn Sci 7:415-423. CrossRef Medline

Edden RA, Muthukumaraswamy SD, Freeman TC, Singh KD (2009) Orientation discrimination performance is predicted by GABA concentration and gamma oscillation frequency in human primary visual cortex. J Neurosci 29:15721-15726. CrossRef Medline

Edin F, Klingberg T, Johansson P, McNab F, Tegnér J, Compte A (2009) Mechanism for top-down control of working memory capacity. Proc Natl Acad Sci U S A 106:6802-6807. CrossRef Medline

Gaetz W, Edgar JC, Wang DJ, Roberts TP (2011) Relating MEG measured motor cortical oscillations to resting gamma-aminobutyric acid (GABA) concentration. Neuroimage 55:616-621. CrossRef Medline

Goldman-Rakic PS (1994) Working memory dysfunction in schizophrenia. J Neuropsychiatry Clin Neurosci 6:348-357. CrossRef Medline

Goldman-Rakic PS (1996) Regional and cellular fractionation of working memory. Proc Natl Acad Sci U S A 93:13473-13480. CrossRef Medline

Guidotti A, Auta J, Davis JM, Di-Giorgi-Gerevini V, Dwivedi Y, Grayson DR, Impagnatiello F, Pandey G, Pesold C, Sharma R, Uzunov D, Costa E, DiGiorgi Gerevini V (2000) Decrease in reelin and glutamic acid decarboxylase67 (GAD67) expression in schizophrenia and bipolar disorder: a postmortem brain study. Arch Gen Psychiatry 57:1061-1069. CrossRef Medline

Harris AD, Glaubitz B, Near J, John Evans C, Puts NA, Schmidt-Wilcke T, Tegenthoff M, Barker PB, Edden RA (2014) Impact of frequency drift on gamma-aminobutyric acid-edited MR spectroscopy. Magn Reson Med 72:941-948. CrossRef Medline

Hartman KN, Pal SK, Burrone J, Murthy VN (2006) Activity-dependent regulation of inhibitory synaptic transmission in hippocampal neurons. Nat Neurosci 9:642-649. CrossRef Medline

Hashimoto T, Arion D, Unger T, Maldonado-Avilés JG, Morris HM, Volk DW, Mirnics K, Lewis DA (2008) Alterations in GABA-related transcriptome in the dorsolateral prefrontal cortex of subjects with schizophrenia. Mol Psychiatry 13:147-161. CrossRef Medline

Heberlein K, Brown MA (2009) Siemens Applications Guide, Spectral Editing with SVS, MAGNETOM TaTs and Verio Systems (3T), syngo MR Numaris 4 VB17A. Available from: http://narr.bmap.ucla.edu/docs/ Appl_Guide_WIP_N4_529_VB17A_SVS_EDIT.pdf. Accessed: September 1,2012 .

Henry PG, Dautry C, Hantraye P, Bloch G (2001) Brain GABA editing without macromolecule contamination. Magn Reson Med 45:517-520. CrossRef Medline

Howard MW, Rizzuto DS, Caplan JB, Madsen JR, Lisman J, AschenbrennerScheibe R, Schulze-Bonhage A, Kahana MJ (2003) Gamma oscillations correlate with working memory load in humans. Cereb Cortex 13:13691374. CrossRef Medline

Lau CG, Murthy VN (2012) Activity-dependent regulation of inhibition via GAD67. J Neurosci 32:8521-8531. CrossRef Medline

Lewis DA, Gonzalez-Burgos G (2006) Pathophysiologically based treatment interventions in schizophrenia. Nat Med 12:1016-1022. CrossRef Medline

Lewis DA, Hashimoto T, Volk DW (2005) Cortical inhibitory neurons and schizophrenia. Nat Rev Neurosci 6:312-324. CrossRef Medline

Lewis DA, Cho RY, Carter CS, Eklund K, Forster S, Kelly MA, Montrose D (2008) Subunit-selective modulation of GABA type A receptor neurotransmission and cognition in schizophrenia. Am J Psychiatry 165: 1585-1593. CrossRef Medline

Linden DE, Bittner RA, Muckli L, Waltz JA, Kriegeskorte N, Goebel R, Singer W, Munk MH (2003) Cortical capacity constraints for visual working memory: dissociation of fMRI load effects in a fronto-parietal network. Neuroimage 20:1518-1530. CrossRef Medline

Luck SJ, Vogel EK (1997) The capacity of visual working memory for features and conjunctions. Nature 390:279-281. CrossRef Medline 
Meltzer JA, Zaveri HP, Goncharova II, Distasio MM, Papademetris X, Spencer SS, Spencer DD, Constable RT (2008) Effects of working memory load on oscillatory power in human intracranial EEG. Cereb Cortex 18: 1843-1855. CrossRef Medline

Mescher M, Tannus A, Johnson MO, Garwood M (1996) Solvent suppression using selective echo dephasing. J Magn Reson Imaging 123:226-229. CrossRef

Mescher M, Merkle H, Kirsch J, Garwood M, Gruetter R (1998) Simultaneous in vivo spectral editing and water suppression. NMR Biomed 11:266272. Medline

Michels L, Martin E, Klaver P, Edden R, Zelaya F, Lythgoe DJ, Lüchinger R, Brandeis D, O'Gorman RL (2012) Frontal GABA levels change during working memory. PLoS One 7:e31933. CrossRef Medline

Minzenberg MJ, Firl AJ, Yoon JH, Gomes GC, Reinking C, Carter CS (2010) Gamma oscillatory power is impaired during cognitive control independent of medication status in first-episode schizophrenia. Neuropsychopharmacology 35:2590-2599. CrossRef Medline

Murray JD, Anticevic A, Gancsos M, Ichinose M, Corlett PR, Krystal JH, Wang XJ (2014) Linking microcircuit dysfunction to cognitive impairment: effects of disinhibition associated with schizophrenia in a cortical working memory model. Cereb Cortex 24:859-872. CrossRef Medline

Muthukumaraswamy SD, Edden RA, Jones DK, Swettenham JB, Singh KD (2009) Resting GABA concentration predicts peak gamma frequency and fMRI amplitude in response to visual stimulation in humans. Proc Natl Acad Sci U S A 106:8356-8361. CrossRef Medline

Postle BR (2006) Working memory as an emergent property of the mind and brain. Neuroscience 139:23-38. CrossRef Medline
Rypma B, D'Esposito M (1999) The roles of prefrontal brain regions in components of working memory: effects of memory load and individual differences. Proc Natl Acad Sci U S A 96:6558-6563. CrossRef Medline

Salthouse T (1990) Working memory as a processing resource in cognitive aging. Developmental Review 10:101-124. CrossRef

Tallon-Baudry C, Bertrand O, Peronnet F, Pernier J (1998) Induced gamma-band activity during the delay of a visual short-term memory task in humans. J Neurosci 18:4244-4254. Medline

Volk DW, Austin MC, Pierri JN, Sampson AR, Lewis DA (2000) Decreased glutamic acid decarboxylase67 messenger RNA expression in a subset of prefrontal cortical gamma-aminobutyric acid neurons in subjects with schizophrenia. Arch Gen Psychiatry 57:237-245. CrossRef Medline

Wei Z, Wang XJ, Wang DH (2012) From distributed resources to limited slots in multiple-item working memory: a spiking network model with normalization. J Neurosci 32:11228-11240. CrossRef Medline

Whittington MA, Traub RD (2003) Interneuron diversity series: inhibitory interneurons and network oscillations in vitro. Trends Neurosci 26:676682. CrossRef Medline

Wu Y, Wang W, Díez-Sampedro A, Richerson GB (2007) Nonvesicular inhibitory neurotransmission via reversal of the GABA transporter GAT-1. Neuron 56:851-865. CrossRef Medline

Yoon JH, Maddock RJ, Rokem A, Silver MA, Minzenberg MJ, Ragland JD, Carter CS (2010) GABA concentration is reduced in visual cortex in schizophrenia and correlates with orientation-specific surround suppression. J Neurosci 30:3777-3781. CrossRef Medline 